\title{
Retraction Note: Radiation Sialadenitis Induced by High-dose Radioactive Iodine Therapy
}

Shin Young Jeong • Jaetae Lee

Published online: 15 February 2014

(C) Korean Society of Nuclear Medicine 2014

Retraction Note: Nuclear Medicine and Molecular Imaging, June 2010, Volume 44, Issue 2, pp 102-109

DOI 10.1007/s13139-010-0027-y

The senior author (J. Lee) and the first author (S. Y. Jeong) have retracted this review article due to misconduct. They have discovered multiple instances of misreferencing and misquotation in the text which raise the concern of potential plagiarism.

The online version of the original article can be found under http://dx.doi. org/10.1007/s13139-010-0027-y.

S. Y. Jeong $\cdot$ J. Lee $(\bowtie)$

Department of Nuclear Medicine, Kyungpook National University Hospital, 50 Samduck-dong 2-ga, Jung-gu, Daegu 700-721, Korea e-mail: jaetae@knu.ac.kr 